\title{
DIÁSPORA AFRICANA NO CEARÁ Representações sobre as festas e as interações afetivo- sexuais de estudantes africano(a)s em Fortaleza
}

\author{
Ercílio Neves Brandão Langa \\ Universidade Federal do Ceará, Brasil
}

Resumo: Este estudo de caráter etnográfico analisa as festas e as interações afetivo-sexuais de estudantes africanos e africanas residentes na cidade de Fortaleza, e as relações desses sujeitos com a sociedade de acolhida. A partir da análise das múltiplas representações existentes, encarnadas pelos grupos sociais, africanos e brasileiros, articulo gênero, raça, classe e outras interseccionalidades. Pertencentes a diversos grupos etnolinguísticos, no cenário de migração estudantil, os africanos e africanas não estão inteirados dos limites sociais tradicionais, rompendo com as fronteiras afetivas e de sexualidade estabelecidas. Uma das ideias centrais que avanço neste artigo, é de que tais eventos constituem momentos liminares (Turner, 1974), privilegiados de interações e negociações afetivas entre a juventude africana e a sociedade fortalezense. Fruto das observações, entrevistas e conversas informais, percebo que tais interações articulam raça, etnia, classe, formato de corpo e de cabelo, que se sobrepõem e se intersectam como atributos desejáveis e atraentes, criando correlações diversas. Muitas dessas correlações revelam uma discriminação interseccional que atinge os homens e as mulheres em graus e formas distintos.

Palavras-chave: Estudantes africanos; Imigração; Interações afetivo-sexuais; Interseccionalidades.

\section{Introdução}

Em suma, o metropolitano aceitaria o imigrante se ele fosse invisível e mudo; ora, a partir de certa densidade demográfica, o fantasma adquire uma terrível consistência; ainda mais pelo fato de que, mais seguro por causa do número, ousa, ao contrário, falar alto, e em sua língua natal, a às vezes vestir-se com seu traje tradicional.

Albert Memmi.

A presença de estudantes africanos no estado do Ceará, teve início na segunda metade da década de 1990, com o primeiro grupo oriundo de Angola. Nesse período, vinham somente estudantes de países africanos que falam a língua portuguesa para integrar-se na Universidade Federal do Ceará (UFC), através do Programa de Estudantes Convênio - Graduação (PEC-G). ${ }^{1}$ A partir de 1998, inicia-se a imigração massiva de estudantes

\footnotetext{
${ }^{1}$ Programa de Estudantes Convênio - de Graduação, administrado de forma conjunta pelo Ministério das Relações Exteriores e pelo Ministério da Educação, fazendo parte dele 45 países, com 32 países efetivos que enviam estudantes de África, da América Latina e de Timor-Leste. O continente africano apresenta o maior contingente de alunos, com 20 países que enviam estudantes todos os anos.
} 
bissau-guineenses e cabo-verdianos e, dois anos depois, estudantes são-tomenses, angolanos e moçambicanos.

No início dos anos 2000, há um aumento significativo do número de estudantes africanos residentes no Ceará - particularmente bissau-guineenses devido à instabilidade política vivida no país -, cuja maioria vem estudar em faculdades particulares, com contratos firmados em seus países de origem. O aumento da imigração de estudantes africanos para o Brasil, no início do século XXI, também foi impulsionado pelo discurso governamental do presidente Luiz Inácio Lula da Silva e sua política de cooperação e aproximação com a África. Ao longo dos oito anos do governo Lula, de 2003 a 2010, o intercâmbio estudantil entre o Brasil e países africanos foi intensificado. Em seus dois mandatos, o presidente Lula visitou 27 países africanos, enquanto seu antecessor, Fernando Henrique Cardoso, visitou apenas três países. Tal política de cooperação, em curso, visa particularmente atingir o ensino superior, através de criação de distintos mecanismos, como estágios profissionais, bolsas de estudo e convênios, no sentido de viabilizar a vinda de africanos para estudar no Brasil.

No contexto de diferentes estratégias mobilizadoras, os estudantes africanos saem de seus respectivos países com expectativas acadêmicas em relação ao Brasil, devido ao maior nível de desenvolvimento econômico, tecnológico e de produção acadêmica, alimentando esperanças de facilidade de inserção por conta de uma língua e culturas em comum - a língua portuguesa, a culinária, a religiosidade e a cultura negra trazida pelos escravos a permear a vida brasileira.

Os argumentos usados ao longo do texto partem da análise das representações sociais existentes entre os distintos atores sociais, homens e mulheres africano(a)s e brasileiro(a)s residentes em Fortaleza. Tais representações expressam a forma como cada grupo elabora e expressa a realidade que vivencia, mas também, como cada grupo vê e pensa o outro. São formadas e enformadas no cotidiano, pelas experiências pessoais e grupais, mas também pela mídia, redes sociais e pela história e evidenciadas pelos discursos, estereótipos e comportamentos diante do "outro".

Mourão (2009) analisou os processos de deslocamento de estudantes guineenses e cabo-verdianos em direção ao Brasil, no âmbito do programa PEC-G, durante o período de formação superior. Tendo como foco central as mudanças identitárias vivenciadas por eles em razão da situação de trânsito, estudou o processo de "ressignificação" das identidades e nacionalidades guineenses e cabo-verdianas nos estudantes desses países em Fortaleza. De acordo com a autora, nos anos 2000, os estudantes africanos participantes do convênio com universidades públicas brasileiras se autodenominavam 
"comunidade africana em Fortaleza", incluindo, particularmente, jovens de nacionalidades cabo-verdiana e bissau-guineense, então unidos e voltados para questões comuns, como adaptação e resolução de problemas cotidianos.

Em sua pesquisa sobre conflito e cooperação entre estudantes cabo-verdianos e guineenses em Fortaleza, Baessa (2005) apud Mourão (2009) constata que, devido ao número crescente de estudantes guineenses e cabo-verdianos na cidade, os indivíduos passam a estabelecer maiores distinções entre si, demarcando suas nacionalidades específicas, contrapondo-se à denominação anterior de “comunidade africana”.

Entretanto, o número de estudantes aumentou, com o surgimento de estudantes não conveniados ao PEC-G, que vinham por conta própria estudar em faculdades privadas, fato que ocasionou aquilo Mourão (2009) designa de processos de "fusão e fissão", que levam grupos ora a se unirem, ora a se oporem. De fato, ao longo dos anos, o número de estudantes africanos no Ceará cresceu, constituindo um contingente de imigrantes a tornar-se complexo em sua diversidade. Atualmente, verifica-se um crescente segmento de estudantes de países, classes sociais e credos religiosos distintos, oriundos não apenas de países lusófonos, mas também de países de expressão inglesa e francesa, como é o caso da Nigéria e da República Democrática do Congo.

Nesse contexto, denomino diáspora africana à presença de estudantes - oriundos de Guiné-Bissau, Cabo Verde, Angola, São Tomé e Príncipe, Moçambique, Nigéria, República Democrática do Congo - no Estado do Ceará. Pertencentes a diversos grupos etnolinguísticos, tais sujeitos apresentam identidades multiculturais e distinções de várias ordens a marcar as suas vidas em território cearense. A noção de diáspora que movimento nesta pesquisa, é inspirado nos escritos de autores dos estudos póscoloniais, como Du Bois, Gilroy e Hall.

Na sua acepção original, o termo se reporta à dispersão do povo judeu pelo mundo. Entretanto, a utilização desse termo se referindo às populações afrodescendentes é cunhada por Du Bois (2007), inspirado na condição de populações negras em distintas regiões no continente americano, que vivenciavam condições comuns de subalternidade e opressão, racializadas e discriminadas por conta de seu passado escravo e tinham como principal característica em comum, a experiência do sofrimento causado pela escravidão racial na modernidade. Já Hall (2011) utiliza a noção de diáspora para se referir às identidades heterogêneas dos imigrantes oriundos da região do Caribe na Grã-Bretanha, seus mitos de origem, as necessidades e perigos que enfrentam sob a globalização. Gilroy (2001) estuda a diáspora constituída pelas 
populações afrodescendentes nos territórios que constituem o Reino Unido e EUA, optando pela designação Atlântico Negro.

Esses autores têm em comum o fato de pensarem as populações descendentes de africanos, espalhadas pelo mundo, como uma realidade racial e cultural criada pela memória do terror racial - a moderna escravidão racial e pelo sistema de plantation, na quais o hibridismo seria uma das características principais.

A diáspora africana em Fortaleza é constituída por indivíduos entre os 18 e 35 anos de idade, oriundos do continente africano, majoritariamente do sexo masculino, predominantemente bissau-guineenses e cabo-verdianos, mas com um contingente cada vez maior de mulheres. Tal diáspora nasce do desejo imigrar voluntário por motivos estudantis, legitimada por convênios e acordos de cooperação e, ao mesmo tempo por discursos governamentais dos dois últimos governos brasileiros, de aproximação com “a África”. Dados da Polícia Federal do Ceará do ano 2011, apontam cerca de mil duzentos e sessenta estudantes africanos no estado, dos quais mil cursavam diversas faculdades particulares, cento e trinta estavam integrados na UFC e vinte na Universidade Estadual do Ceará (UECE), sendo a maioria proveniente dos países africanos de língua oficial portuguesa (PALOP) (Brás, 2011).

De fato, o número de africanos se apresenta muito maior do que o cadastrado pela Polícia Federal, pois muitos estudantes se encontram em situação irregular. Geralmente, no ano seguinte de estada em Fortaleza, um número significativo de estudantes não consegue prorrogar o visto de estudante com o qual entrou no Brasil e outros estudantes africanos chegam a Fortaleza vindo de outros estados brasileiros. Uma parcela significativa de estudantes, a maioria, vinculada às faculdades particulares, vivencia condições precárias de vida, em meio a preconceito e discriminação raciais.

A diáspora tem gerado grupos e movimentos, a congregar estudantes africanos em um processo de mobilização e organização em diversas agremiações estudantis, cabendo destacar: a Associação de Estudantes Africanos no Estado do Ceará (AEAC), a Associação de Estudantes da Guiné-Bissau no Estado do Ceará (AEGBECE), a Fundação de Estudantes Cabo-verdianos nas Faculdades do Nordeste (FEAF) e o Movimento Pastoral de Estudantes Africanos (MPEA). Este último movimento, hoje, revela-se com maior articulação e visibilidade, destacando-se em ações de promoção e defesa dos direitos dos estudantes africanos e denunciando as situações por que passam esses sujeitos, por meio de reuniões entre estudantes e faculdades, encaminhamento de processos na justiça e realização de manifestações públicas. 
Estudantes Bissau-guineenses, em relatório elaborado, como estratégia organizativa no âmbito do MPA, assim denunciam expressões de racismo:

Temos enfrentado discriminação racial na cidade, inclusive dentro das próprias faculdades, o que caracteriza racismo institucional, das/os funcionários, professores/es e direção. A direção já chegou a impor regras, para nós, como: tomar banho, usar perfume, creme de pele, não chegar suado/a [...]. Essas exigências só são feitas aos estudantes africanos (Movimento Pastoral dos Estudantes Africanos, 2012, p. 7).

Nota-se entre os cearenses a existência de múltiplas representações acerca da presença africana, destacando-se visões estigmatizantes perpassadas de preconceito racial pela condição de negro, tal como denunciam os estudantes africanos, em relatório elaborado, como estratégia organizativa do MPEA. Entretanto, tais associações estudantis africanas se baseiam em distinções nacionais, conforme o país de origem, revelando-se bastante estéreis ou com pouca capacidade de negociação junto às instituições de ensino superior brasileiras, nas quais, os estudantes estão inseridos. Outra característica de tais associações é a desigualdade de gênero, evidenciada por pouca ou nenhuma participação das jovens africanas nessa diáspora. De fato, as agremiações foram idealizadas e são comandadas por indivíduos do sexo masculino, não havendo uma preocupação com a equidade de gênero.

\section{O Cotidiano dos estudantes africanos em Fortaleza e o encontro com a alteridade}

Chegados ao Brasil, os estudantes africanos enfrentam desafios cotidianos, particularmente, dificuldades econômicas de sobrevivência considerando o elevado custo de vida nesta metrópole, em relação às suas possibilidades financeiras. Parte significativa desse contingente afirma sentir-se discriminada no cotidiano, por conta da cor da pele e da própria origem africana, em graus e formas distintas das discriminações encontradas nos países de origem. Gusmão (2006) abre vias de reflexão, ao circunscrever a própria posição do Brasil, a receber a diáspora africana:

Um país multirracial e integrante dos chamados "países emergentes", mas que se diferencia dos países europeus, até muito recentemente privilegiados na busca por qualificação de quadros por parte dos Palop. Em questão, a posição de um país relativamente periférico na divisão internacional do trabalho, com um passado igualmente de colonização portuguesa e que, estruturalmente mestiço e negro, pensa-se branco e europeu. Em debate, a existência de processos intensos de 
discriminação e racismo na realidade brasileira e a percepção e a vivência do sujeito negro e africano nesse contexto (Gusmão, 2006, p. 16).

Os estudantes africanos integrados às universidades federais e estaduais, que constituem, de fato, a minoria, sobrevivem das bolsas do PEC-G e de outros convênios firmados entre o Brasil e seus países de origem. Já o segmento maior, que estuda em faculdades particulares, recebe dinheiro das famílias para pagar mensalidades e manter-se na faculdade, complementando a sua renda por meio de trabalhos clandestinos - em lojas e mercadinhos, salões de beleza, oficinas, fábricas e construções, restaurantes ou mesmo, nos estacionamentos de grandes shoppings centers e supermercados, ou, ainda, em "casas de família” como babás - para assim, garantir a sobrevivência e a própria locomoção na cidade. Vejamos o depoimento de uma estudante cabo-verdiana de 31 anos de idade, residente em Fortaleza há cerca de cinco anos, onde cursa Administração em uma faculdade particular e trabalha numa entidade pública na condição de estagiária:

Eu me mantenho no Brasil trabalhando. Eu recebo uma parte do dinheiro da minha família, eu tenho apoio dos meus irmãos, do meu pai e do meu namorado. Esse dinheiro é para pagar faculdade e está incluso o dinheiro para pagar quitinete. Quando demora sair meu salário, aí eu ligo pra minha família e digo que está faltando dinheiro, aí eles me ajudam. O dinheiro que eu confio mais é aquele que eu trabalho. O dinheiro da família é complementar. Eu estou aqui no Brasil há 5 anos. (Entrevista gravada em 13/03/2013).

Dentro deste grupo de estudantes, inseridos nas faculdades particulares, existe um segmento de jovens que, nos tempos livres, dedica-se ao comércio de roupas e calçados entre o Brasil e seus países de origem. Por fim, um grupo seleto de estudantes de faculdades particulares, com destaque para os cabo-verdianos, sobrevive e estuda de forma tranquila, graças ao dinheiro enviado por familiares residentes em África e por parentes imigrantes em países da Europa e América do Norte.

As faculdades particulares, - como mecanismo de atração - dizem garantir estágios remunerados para estudantes ao final dos cursos de Administração, Contabilidade, Marketing, Comunicação, Ciências e Gestão de Informação. Na realidade, são oferecidos aos estudantes africanos, "estágios remunerados" que são formas de trabalho precário como panfleteiros, vigias de lojas nos shoppings centers e em estacionamentos ou como operadores de vigilância eletrônica, em um artifício usado para contornar a norma que os proíbe de trabalhar. Vejamos o extrato de entrevista com uma estudante bissau-guineense de 27 anos de idade que concluiu o curso de 
Técnica de Enfermagem. Na altura da entrevista residia em Fortaleza há quatro anos e, estagiava como enfermeira em um hospital particular de Fortaleza:

No estágio tá tudo bem, só que eles não pagam há sete meses no estágio. Há sete meses no estágio sem nada, sem pagar nada. Nunca tive problemas com a Policia Federal, com eles não. Sempre fui bem tratada. Tudo ok. Às vezes, as pessoas ficam olhando assim como se fosse uma coisa do outro mundo que ele nem conhece. Aquela admiração. Às vezes, eu sinto algum preconceito. Mas eu não tô nem aí. Eu fico na minha porque eu sei o que é que eu quero na vida. Não vou ficar com a pessoa só fazer preconceito comigo não. Problema é dela, ela é que sabe. Atualmente, aqui, agora não estou a estudar porque eu já terminei de fazer o curso técnico e estou sem dinheiro pra fazer a faculdade, que é muito cara. A mensalidade é de 800 reais, 750 reais, dependendo da faculdade. Tem de 600 reais. Eu quero entrar no curso superior, fazer faculdade, que agora eu fiz o curso técnico. [...]. Agora eu não trabalho, estou no estágio. O estágio não é remunerado. Eu gosto do meu trabalho, gosto muito. Da minha área eu gosto. (Entrevista gravada em 19/03/2013).

As dificuldades e distintas formas de discriminação enfrentadas pelos jovens estudantes, suas interpelações raciais e ressignificações identitárias assemelham-se aquilo que Turner (2005) define como dramas sociais, isto é, dificuldades de se recriar universos sociais e simbólicos no mundo contemporâneo, onde os indivíduos se veem sozinhos e abandonados diante da responsabilidade de darem sentido à sua vida. $\mathrm{O}$ drama social seria uma experiência vivida que remete à noção de perigo, propiciando aos indivíduos acesso ao universo social e simbólico, que opõe o cotidiano ao extraordinário.

No cotidiano, os estudantes africanos percebem a dificuldade dos brasileiros em chamá-los pelos nomes próprios, substituindo-os pela categoria nativa brasileira “negão" e facilmente esquecem as nacionalidades e os nomes dos países de origem, diluindo tudo na categoria genérica de africano. Entretanto, tal situação não expressa, necessariamente, discriminação ou racismo, visto que, o esquecimento dos nomes próprios dos estudantes, seus países e nacionalidades de origem pode dever-se também ao desconhecimento ou até ignorância da parte de cidadãos brasileiros negros e brancos. Mendes (2010), em seus estudos sobre o racismo no Ceará, bem enfatiza que:

Os estudantes africanos não estão inteirados dos limites sociais tradicionalmente construídos pelos brancos para segregar os negros. Não estão informados desses espaços de exclusão, eles rompem as fronteiras estabelecidas e transitam em espaços brancos. (Mendes, 2010, p. 27). 
Os estudantes africanos, nos percursos cotidianos em Fortaleza, também percebem a distância social dos brasileiros negros que, muitas vezes, acreditam que os africanos são playboys, sujeitos ricos oriundos das elites políticas africanas, ou então são indivíduos que vêm ao Brasil ocupar os lugares que, por direito, seriam seus. Existe ainda entre os brasileiros negros a representação de que os africanos são cotistas, isto é, estudantes beneficiários das cotas raciais no ensino superior no Brasil.

A rigor, as formas de interação dos estudantes africanos com a população cearense, no cotidiano, tende a expressar mecanismos de discriminação, colocando-os na posição de outsiders (Elias \& Scotson, 2000). Nota-se entre os cearenses a existência de múltiplas representações acerca da presença africana, destacando-se visões estigmatizantes perpassadas de preconceito racial pela condição de negro. Sustento a hipótese de que, ao longo de suas trajetórias em Fortaleza, os africanos gestam diferentes configurações identitárias e afetivas, negociando-as em distintos momentos e situações: na rua, no contexto universitário, particularmente, nas festas africanas e relacionamentos.

\section{Festas africanas, atores, cabelos, roupas e músicas}

As festas ou "noites africanas" representam momentos de confraternização para rever amigos e conhecidos, matar saudades da terra de origem através das músicas, danças e comidas, mas também para união e resolução de conflitos. Acontecem, em Fortaleza, pelo menos dois eventos por mês, sejam eles "menores" com até trinta pessoas ou "grandes", com mais de cem pessoas, sendo organizados via contribuição individual em dinheiro ou bebidas ou ainda, a partir da venda de ingressos que custam o entre 10 a 50 reais. As festas menores realizam-se em casa dos estudantes, enquanto que as grandes se realizam em centros sociais, clubes ou discotecas alugados.

As confraternizações comemoração do 25 de Maio - dia de África - e dos dias da independência dos países africanos com maior quantitativo de estudantes representados, apresentam-se como as maiores confraternizações anuais, com a participação de centenas de pessoas entre estudantes africanos, brasileiras e brasileiros e, às vezes, alguns turistas europeus, de países sul-americanos e das Guianas. Geralmente, tais festas são acompanhadas de muito álcool- cerveja, bebidas secas, cachaças, whiskies de marcas pouco conhecidas ou até duvidosas e refrigerantes.

Durante os eventos, quase sempre, falta comida ou ela acaba 30 minutos após começar a ser servida aos convidados, ainda que os organizadores se esforcem por oferecer pratos típicos da Guiné-Bissau como caldo mancarra e caldo cacheu ou a katchupa cabo-verdiana. Também são servidos arroz branco, arroz refogado e galinha frita, assim 
como salgadinhos brasileiros. Poucas vezes são servidos bolos ou comidas típicas cearenses, como o "baião de dois" ou a "panelada". Já os "bailes" e "noites" africanas são eventos menores que ocorrem, regularmente, em média duas vezes a cada mês, em clubes noturnos e discotecas de Fortaleza.

De fato, tais eventos constituem momentos privilegiados de interações e negociações identitárias entre estudantes africanos e sociedade cearense. A maioria dos indivíduos presentes nas festas são homens e mulheres bissau-guineenses e, em seguida as mulheres brasileiras. Longe de casa, os africanos e africanas podem ouvir e dançar músicas e degustar comidas tipicamente africanas, além de sentirem-se livres para se relacionar com pessoas independentemente de país, etnia, raça, idade e orientação sexual. E, de fato, ocorrem, com mais intensidade, as interações afetivo-sexuais entre africanos e africanas, mas também entre africanos(as) e brasileiros(as), envolvendo particularmente mulheres brasileiras mais velhas, designadas por coroas, e moças das classes populares em interações com jovens africanos. São momentos de encontro para além de discriminações, em meio à música e performances das danças e expressões afetivo-sexuais.

Tais eventos assemelham-se àqueles que Turner (1974) designa como "momentos liminares", pois ocorrem sociabilidades interétnicas e interaciais entre africanos e africanas de diferentes países e etnias e, particularmente, entre africanos e brasileiras. O autor usa essa expressão para designar as fases dos rituais de passagem em grupos tribais e períodos em que os indivíduos transitam em uma ambiguidade de status, distanciando-se e, em seguida, reaproximando-se da estrutura social, perdendo seu status. Turner compara a liminaridade à morte e a invisibilidade, pois, nessas situações, os indivíduos não possuem mais o status e se distanciam simbolicamente da estrutura hierárquica da sociedade, passando a um estado de comunhão entre os indivíduos.

A roupa é um adereço fundamental nas festas, nas quais, africanos e brasileiras dificilmente se descuidam nesse quesito. Normalmente, os homens africanos vestem roupas ocidentais, calças de ganga ou social, assim como ternos, gravatas, chapéus clássicos ou bonés mais contemporâneos dos rappers norte-americanos, e até estilos clássicos de roupa social constituída de calças com suspensórios. Já a maioria das moças africanas traja roupas ousadas, shorts e saias curtas, vestidos decotados apertados a seus corpos típicos da cultura das mulheres brasileiras, acompanhados de sapatos de salto alto e outros adereços como colares, bolsas, muito brilho, batons e bem maquiadas. 
Neste contexto, percebo que ao longo dos anos, durante as festas, as mulheres africanas tem adotado trajes de roupa, estilo mulher brasileira gostosa - roupas curtas e ousadas que se ajustam ao corpo. Por sua vez, as mulheres brasileiras adultas e jovens das classes populares, sensualizam com seus vestidos curtos e outras vestidas de blusas e shorts jeans bastante curtos os quais, exibem seus corpos, barrigas, etc. Nas últimas festas, quase nenhum africano ou africana traja mais roupas típicas de seu país de origem, contrastando com os anos anteriores, em que muitos africanos e africanas trajavam roupas típicas de seu país. Assim, verifica-se transição no uso de roupas africanas coloridas, para um estilo mais formal, totalmente ocidentalizado.

Além da roupa, o cabelo revela ser um adereço importante. Entre os africanos do sexo masculino, há uma tendência em mexer no cabelo, trançando-os ou fazendo em estilo dreadlocks, mais conhecido por dreads ou rastafári, mais conhecido por rastas. Parte dos estudantes aparece na festa de cabelo bastante curto ou até raspado. Já entre as mulheres africanas verificam-se várias tendências, a primeira é o alisamento dos cabelos estilo chapinha. Outra tendência é a implantação de cabelos enrolados verticalmente, cujas pontas são pintadas de louro num estilo conhecido como mega grefage.

Esse último estilo, muito comum nas meninas guineenses, cujo cabelo é importado desse país africano. A utilização de perucas também é uma prática cada vez notória entre as africanas que, portam perucas de cabelos curtos e liso em forma de tigelas, com franjas caídos até às orelhas e compridas na parte traseira. Entretanto, a grande moda dominante no momento são os apliques e extensões de cabelos castanhos e pretos, ao estilo da cantora negra norte-americana Beyonce.

A festa africana é rica em estilos musicais, toca-se música africana como zouk, passadas, gumbê e kuduro e, música brasileira como funk, sertanejo e forró, mas também toca-se música eletrônica de discografia europeia. O zouk, estilo com origem nas Antilhas francesas é dançado "bem agarradinho" por duas pessoas de sexo diferente, no qual as mãos são colocadas na cintura. Quando se toca zouk, os africanos parecem reinar, pois, representa o momento da performance, de mostrar harmonia de tronco, traseiro e pernas, de balançar os glúteos suavemente. Esse estilo de música cria conflitos, pois, a sensualização, o ato de passar a mão entre a cintura e a bunda nem sempre é visto com bons olhos entre os brasileiros, homens e mulheres. Normalmente, cabe às mulheres africanas "arrasar" durante esse estilo de música, dar um "chega pra lá” nas mulheres brasileiras. 
Já o kuduro, um estilo de dança criado em Angola na década de 1980 ocupa um lugar especial na festa. Mesmo não sabendo dançar, quase todos inventam o seu próprio estilo. O kuduro representa subversão e crítica social, é dançado individualmente sem contato físico entre homens e mulheres, cantado em calão e gírias angolanas, uma mistura de português com as línguas nacionais, parecido com o break norte-americano misturado com danças africanas. Por seu um estilo de música oriundo das classes populares e nunca foi aceite pela elite mais educada e abastada angolana (Guiot, 2009).

Algumas letras de kuduro são obscenas ou caricaturadas que abordam o cotidiano falta de dinheiro, usar roupas de marcas falsificadas, traição entre casais, aumento do custo de vida, etc. Quando toca a música, os africanos fazem um círculo, onde um deles entra no meio e faz um passo de dança com as mãos e os pés, enquanto os outros ficam assistindo batendo palmas, se revezando, entrando e saindo do círculo.

O kuduro não tem nada de sensual, pelo contrário, é improvisado e inventado no momento - seus dançarinos fingem ter membros do corpo, pernas ou mãos quebrados, imitam o andar de um esqueleto, etc. - em gestos muito habilidosos, lembrando o estilo break. Por sua vez, o funk é dançado por todos, suas músicas fazem enorme sucesso entre todos africanos, brasileiros e outras nacionalidades. Quando dançam, as mulheres inclinam a cabeça e o tronco para a frente, realçam e balançam os glúteos, algumas vezes com gestos sexualizados. Nesse estilo não se faz roda, normalmente, os homens ficam acochados por detrás das mulheres, sempre imitando gestos sexuais. De fato, o kuduro e o funk se aproximam na festa africana. Elas representam subversão aos valores aceitos na sociedade e ser oriundas das classes populares, são estilo de músicas de subversão. O kuduro é maioritariamente dançado por homens africanos com seus passos criativos, ao passo que o funk é dominado pelas mulheres brasileiras, com seus glúteos.

As festas e bailes africanos constituem momentos e espaços de liminaridade, de subversão às normas, nas quais, africanos e africanas e brasileiro(a)s confraternizam namoram, ficam, dançam sem os controles sociais vigentes no cotidiano e os olhares discriminatórios. De acordo com Turner (1974), a liminaridade resulta de uma subversão a uma ordem estrutural, ela é cíclica, ocorrendo em momentos nos quais os indivíduos libertam sua criatividade. Nas obras deste autor, a liminaridade é comparada à morte e à invisibilidade, pois, nessas situações, os indivíduos não possuem mais o status e, distanciam-se simbolicamente da estrutura hierárquica da sociedade, passando para um estado de comunhão e igualdade entre os indivíduos, que ele designa de communitas. A subversão ou oposição às normas torna 
temporariamente aceitáveis, permissíveis ou toleráveis práticas que, habitualmente consideradas indesejáveis ou não recomendáveis.

\section{As interações afetivo-sexuais entre africanos e mulheres brasileiras}

Nos encontros cotidianos, em diferentes situações e circunstâncias, cearenses e africanos, de ambos os sexos, olham-se de forma ambivalente, discriminando-se e sexualizando-se. Nas interações, os estudantes africanos, na condição de negros e imigrantes, portanto, sujeitos marginais, são colocados em posição inferior e de subalternidade, ocupando um lugar secundarizado em termos de preferências afetivas para relacionamentos estáveis. Ao mesmo tempo em que são objeto de estigma, os estudantes africanos são também objeto de desejo sexual para encontros fortuitos, sem compromissos afetivos.

Durante os encontros, há um esforço de africanos e de brasileiras para caber nos estereótipos existentes acerca da insaciabilidade sexual do "outro", havendo interesses e curiosidades mútuos pelo "diferente" - no tocante à cor da pele, etnia, cabelo, formas corporais e até origem social -, nos quais, a iniciativa da "paquera" pode iniciar tanto do homem africano, como da mulher brasileira. Contudo, o mesmo não acontece entre africanos e mulheres negras brasileiras, onde há certo distanciamento, verificando-se poucas interações entre esses dois grupos. Ao explicar o papel da representação dos estereótipos nas sociedades coloniais, Bhabha (2010) argumenta:

A pele, como o significante chave da diferença cultural e racial no estereótipo, é o mais visível dos fetiches, reconhecido como "conhecimento geral" em uma série de discursos culturais, políticos e históricos, e representa um papel público no drama racial que é encenado todos os dias nas sociedades coloniais. Em segundo lugar, pode-se dizer que o fetiche sexual está intimamente ligado ao "objeto bom"; é ele o elemento do cenário que torna o objeto todo desejável e passível de ser amado, o que facilita as relações sexuais e pode até promover uma forma de felicidade. (Bhabha, 2010, p. 121).

Por sua vez, africanos desenvolvem olhares estigmatizantes em relação, à população composta por gays, lésbicas, bissexuais e travestis (LGBT). No entanto, no âmbito da presença africana, tem-se, ainda com menor expressão e visibilidade, trocas de olhares entre africanos(as) e brasileiros(as) do mesmo sexo que, assumem distintas identidades como homossexuais, gays, e lésbicas, em relações veladas, subterrâneas, não assumidas em público. Vejamos o depoimento de um cidadão brasileiro de 35 anos de idade trabalhador em call center, assíduo em festas africanas. 
Eu sempre gostei de vocês aqui, das vossas festas [africanas]. Comprei o ingresso e vim. Foi massa! No meio da festa fui pedir cerveja, e o africano que estava no balcão respondeu friamente que não tinha cerveja, mas eu sei que tinha porque ele dava aos amigos. De repente um africano que estava atrás de mim, na fila, apercebeu-se que eu queria cerveja, ele passou a mão na minha cintura com força, com aquela "mão". Pediu duas cervejas e, me ofereceu a outra cerveja. Eu olhei pra ele e ele se fez de desentendido, mas eu percebi tudo. [Grifos do pesquisador]. (Extrato de conversa informal, gravada em 09/10/2011).

Uma via investigativa fecunda é considerar o universo simbólico que circunscreve os negros no imaginário brasileiro. A rigor, os olhares que discriminam e, ao mesmo tempo, sexualizam negros e negras africanas têm raízes históricas no Brasil, remontando ao período da escravidão, com ressignificações contemporâneas. De fato, as relações afetivo-sexuais entre africanos(as) e brasileiros(as) são dominadas por representações hipersexualizadas acerca do "outro", no tocante às performances, aptidão e tamanho dos órgãos sexuais, revelando desejo e fetiche sexual acerca do homem africano, tido, no imaginário social, como "bom de cama", insaciável, com performances sexuais acima da média e sempre disponível para satisfazer fantasias de mulheres e homens cearenses. Vejamos, em seguida, o extrato da conversa com uma mulher brasileira de quarenta anos de idade, servidora pública que, explicita em parte, o imaginário social brasileiro representado em relação aos africanos:

Eu gosto mesmo é de negro. Essa pele [levou o dedo indicador à língua e em seguida esfregou nos braços do pesquisador]. Sou fã do Akon [músico nigeriano radicado nos EUA], adoro as suas músicas, tenho um DVD só com as músicas dele. Veja no meu Orkut, só tem negro. Se eu pudesse... É pena, o M. [estudante africano] fugiu de mim. Vocês nunca me convidam para as vossas festas. No dia que eu for, vou ficar doida com tanto negro para escolher. [Grifos do pesquisador]. (Extrato de conversa informal gravada em 28/05/2011).

Já na diáspora africana, o Brasil é visto como um lugar exótico, país do carnaval e da sexualidade liberada, caracterizado pela diversidade sexual e de gênero. Durante os momentos de interação, há esforço de africanos e de brasileiros para encarnar estereótipos existentes acerca da sexualidade do outro, dominados por curiosidade e interesses mútuos onde a raça é peça fundamental da diferença cultural. Nesse tipo de busca, e aproximações, a iniciativa pode partir tanto de africanos, assim como de brasileiros. Tais encontros articulam gênero, raça, etnicidade e são mediados por sexo, afetos, presentes e dinheiro (Piscitelli et al., 2011). 
É fato inconteste que raça, sexo, formas corporais e cabelos apresentam-se como fatores de atração, existindo preferência de africanos por mulheres brasileiras corpulentas, de pernas grossas, de pele mais clara e, particularmente, por mulheres louras. Nesse mercado sexual, africanos têm preferência por mulheres brasileiras brancas em detrimento das brasileiras negras e das mulheres africanas.

Quando eu começo a ficar com as pessoas, eu fico, acabo. Rapaz, eu tipo, assim, ficar sério, serio, tipo assim, eu já fiquei sei lá, umas 30 ou 40 meninas, entende. [...] Brasileiras, elas são menos ciumentas, tipo, eu também sempre estabeleço: superfície, não vamos aprofundar. Naturalmente, elas são gostosas, elas gemem bem. Entendes? Nas africanas percebi um processo cultural mais intenso, elas são menos liberais. Entendes? O processo cultural delas é aquela coisa de família, casar, ter filhos e isso também repercute. Elas não ficam, elas querem namorar, querem casa, essas coisas entendeu? Já as brasileiras estão aí prá vida, querem curtir, querem pegar negão, essas coisas. Entendeu? Aí, tipo, cara eu só não gosto de gorda, favelada, tipo nesse sentido... que eu percebo que tem ah... incomível e gordas, entendes? São esses três tipos de mulheres que eu não gosto. Mas conversando, conhecendo pessoas, tipo, pode ter exceções, entendes? Então, eu sempre me deixei levar pelo meu cabelo, meu cabelo sempre foi meio doido. Eu cresci influenciado também por essa moda. Eu não quero ser gordo, eu queria ter um cabelo black, assim grande, mas tô ficando careca. Nas mulheres, assim eu já fiquei com mulher loira e tava gostando do cabelo dela. Aí fiquei com uma menina de cabelo curto e passei a achar bonito as mulheres de cabelo curto, varia. Entende? (Extrato de entrevista gravada em 15/11/2013).

Em seu habitus (Bourdieu, 2003), os estudantes africanos tendem a gostar de "mulheres cheinhas", com carne, com seios e bundas avantajadas, tal é tipo ideal de mulher gostosa, propalada pelos africanos. Já entre mulheres brasileiras, existe a atração por africanos de pele mais escura, pelos mais altos e de corpo atlético, não distinguindo a etnia ou classe social. E cabe considerar que essa diáspora assume expressões heterogêneas, com estudantes de diferentes países, regiões e culturas, embora, ao mesmo tempo, tais sujeitos apresentem aspectos comuns, um habitus africano, como princípio a estruturar modos de viver, no contexto de imigração.

Normalmente, as brasileiras que se interessam pelos estudantes africanos são mulheres brancas mais velhas, coroas, mas também moças das classes populares, mulheres gordas, ou que não se enquadram no ideal estético e de beleza vigentes na sociedade brasileira. Algumas dessas mulheres possuem uma renda mediana ou alta, poder de compra e de consumo, carro, casa própria, carreira profissional, condições que, muitas vezes, atraem os "caça-brasileiras", jovens estudantes africanos que somente se 
relacionam afetiva e sexualmente com mulheres brasileiras. A expressão "caçabrasileiras" é inspirado em Cantalice (2009), na sua análise acerca das interações afetivo-sexuais entre jovens brasileiros e turistas do sexo feminino de países nórdicoeuropeus.

Tais preferências afetivo-sexuais, fundadas em determinados atributos tidos como desejáveis e atraentes - raça, origem, cor do cabelo, formato do corpo, classe, posição social, renda e outras formas de afirmação e diferenciação - encarnam múltiplas expressões discriminatórias, configurando aquilo que Crenshaw (2002) e Piscitelli (2008) designam de "discriminação interseccional ou interseccionalidade".

Crenshaw (2002) argumenta que as discriminações de raça, etnia, gênero, classe, renda, não são mutuamente excludentes, e assim, muitas vezes se sobrepõem e se intersectam, criando complexas conexões onde se juntam dois, três ou mais elementos. Assim, a autora propõe a noção de discriminação interseccional como uma ferramenta capaz de circunscrever hibridizações nos processos discriminatórios. Tomando como exemplo a discriminação racial, Crenshaw aponta que, em determinados contextos, esse fenômeno se apresenta de maneira específica e diferenciada para os indivíduos, atingindo, de formas distintas, homens e mulheres.

Já Piscitelli (2008) propõe a interseccionalidade como categoria analítica para apreender a articulação de múltiplas formas de diferenças e desigualdades, esclarecendo que em muitas situações, não se trata somente de discriminação racial, étnica, sexual, de gênero ou de classe em esferas separadas, mas, sim, da diferença em seu sentido amplo a articular múltiplas expressões de discriminação. Tal noção se baseia na premissa de que as pessoas têm identidades múltiplas, derivadas das relações sociais, históricas e estruturas de poder, experimentando de forma diferente as várias formas de dominação e discriminação nas suas trajetórias.

Cumpre salientar que as interações entre jovens africanos e mulheres e homens brasileiros também ocorrem em meio a tensões e choques culturais e, alguns africanos e africanas sentem-se usados em relacionamentos permeados de poder e de dominação simbólicos (Bourdieu, 2002). Nessas relações, as mulheres brasileiras bancam quase tudo, ou seja, pagam as contas no cotidiano, em supermercados, lojas, restaurantes, aluguel de apartamentos, mensalidades das faculdades e outras formas de ajuda.

O fato de mulheres brasileiras não assumirem, publicamente, o relacionamento afetivo com africanos, o caráter descartável das relações, o ficar - relações fugazes e fluídas que podem durar de algumas horas a uma semana, ou um mês no máximo, são outras situações que representam violência simbólica (Bourdieu, 2002), que atinge os homens 
africanos na sua autoestima, ao mesmo tempo que viabilizam melhores condições de vivência na diáspora.

A violência simbólica se institui por intermédio da adesão que o dominado não pode deixar de conceder ao dominante quando ele dispõe - para pensar e para se pensar, ou para pensar a sua relação com ele - mais do que instrumentos de conhecimento que ambos têm em comum e que, não sendo mais que a forma incorporada da relação de dominação, faz esta relação ser vista como natural. Assim, as classificações são incorporadas e naturalizadas, como por exemplo, alto/baixo, masculino/feminino, negro/branco (Bourdieu, 2002, p. 43).

Todavia, as relações fugazes não afetam somente os africanos, mas os homens em geral, Os homens africanos parecem ainda não estar habituados a essas relações. Nesse padrão de interação, são as brasileiras quem mandam e ditam os momentos, as circunstâncias e os lugares em que estas relações podem ocorrer. Nesses processos, os homens africanos terminam por experienciar posições inversas que as assumidas no contexto das suas terras de origem, perpassadas de configurações machistas, de dominância e mando.

\section{Afetividades subalternizadas: as moças africanas e o mercado afetivo}

Nas interações afetivo-sexuais vivenciadas pelas estudantes africanas, verificam-se diversas formas de arranjos, desde namoros com africanos, seja do mesmo país e etnia, assim como com homens brasileiros, muitas vezes, em nítidas relações de submissão a envolver dependência econômico-financeira. As moças africanas costumam relacionarse, particularmente, com homens que contribuam para seu equilíbrio financeiro. Nesse cenário, percebo que as mulheres negras, particularmente as africanas, ocupam o último lugar em termos de preferências afetivas em Fortaleza. Tal situação pode ser reflexo da representação histórica, existente sobre a mulher negra na estrutura social da sociedade brasileira que, por sua vez, parece ser incorporada pelos homens africanos.

Pesquisas de Berquó (1987) chamam atenção para a existência de um maior quantitativo de mulheres negras morando sozinhas no Brasil, na condição de viúvas, solteiras ou separadas. A este fenômeno afetivo, Silva (2008) designa metaforicamente de "solidão da mulher negra". Na ótica da autora, tal "solidão" ocorre por conta da subjetividade e preterimento afetivo de mulheres negras por parte de homens negros e brancos, numa sociedade brasileira racialmente hierarquizada. Atualmente, além desse fator, são acrescidos outros, como o fato da maior parte dos jovens negros ser oriunda das classes populares, onde os laços afetivos se desfazem com mais facilidade. 
Entretanto, o fator mais destacado são as mortes violentas e homicídios dos jovens negros, que concorrem para a alta taxa de mortalidade dos homens, um fenômeno designado por "extermínio/genocídio da juventude negra”. De fato, no Brasil, a maior parte da população negra, em quase todas as dimensões de sua existência, vivencia situações de exclusão, marginalidade e/ou discriminação socioeconômica, o que os coloca em posição de maior vulnerabilidade frente a uma série de agravos à saúde. Esse população ocupa posições menos qualificadas e pior remuneradas no mercado de trabalho, residem em áreas com menos infraestruturas básicas e sofrer maiores restrições no acesso a serviços de saúde. (São Paulo, 2011).

Já Fanon (1983) demonstra a existência de um número de frases, provérbios e linhas de conduta que regem a escolha de um namorado branco, entre as mulheres negras e, a consequente rejeição do homem negro, em sociedades pós-coloniais. O autor chama atenção para a condição de submissão das mulheres negras nos relacionamentos com homens brancos, pois, seriam caracterizadas pelo sentimento de inferioridade interiorizado pelas últimas. Na sua ótica, a mulher negra entra nesses relacionamentos numa posição desigual, sendo sempre desprezada e nunca tolerada no meio social branco, cujo amor pelo homem branco seria impossível e proibido em todas as sociedades. Via de regra, as estudantes africanas apresentam escolhas afetivas distintas e independentes da raça, mas, revelam preferências por aspectos como classe social e etnia. Assim, entre estas, verificam-se poucos relacionamentos com homens de países distintos dos seus, ou por homens com pouco poder econômico.

Diante da experiência de preterimento afetivo, as jovens africanas apresentam diversas estratégias de autoestima e inserção no mercado afetivo, que vão do investimento na estética e valorização da aparência pessoal, a frequência à salões de beleza e academias de ginástica, dentistas, ao uso de diversos acessórios como óculos, pulseiras, colares, bolsas. Assim como por meio de trajes e roupas abrasileiradas ousadas, - vestidos com decotes ousados, saias e shorts curtos - ou de roupas africanas coloridas, mas também, através do uso de cosméticos da linha blackpower, tranças africanas, apliques, extensões e mechas nos cabelos.

Como diria De Certeau (1998), as mulheres africanas têm as "suas estratégias e táticas" de inserção e sobrevivência no mercado afetivo-sexual de Fortaleza. De fato, em seus relatos, as mulheres africanas apontam diferenças significativas nos seus relacionamentos com homens africanos e com brasileiros, nos quais, os últimos aparecem como mais carinhosos menos algozes, demonstrando assim, que trocam olhares, "flertam" e interagem com homens brasileiros. 
Nesses relacionamentos percebe-se a sua preferência por homens de certa classe social ou poderio econômico, ou que sejam sensíveis à sua condição financeira, mas também por homens que trabalhem e que contribuam para pagar as despesas cotidianas. Em tais relações, parece haver certa preferência por homens brasileiros, por representarem maiores oportunidades de inserção, contatos e conhecimentos na cidade. É necessário ressaltar o papel da violência, que parece permear e estruturar suas relações afetivas com homens africanos, tidos como "brutos".

De fato, são notórias as queixas de mulheres africanas e brasileiras sobre a violência nos relacionamentos com homens africanos. Nos discursos das africanas, percebe-se produção e representação do homem brasileiro como ideal - carinhoso, diferente, mas também ciumento -, criando-se uma escala hierarquizada de "brutalidade masculina" diferenciada entre os homens brasileiros e homens africanos.

Entretanto, suas falas parecem ignorar ou invisibilizar a "brutalidade" advinda do relacionamento com o homem brasileiro de maior poderio econômico. Assim como são incontestes os episódios de violência física de homens africanos em seus relacionamentos com mulheres africanas e brasileiras. Tal fato torna-se visível pela quantidade de denúncias feitas por amigos e vizinhos, assim como pelos Boletins de Ocorrência abertos por mulheres brasileiras, na única Delegacia da Mulher existente em Fortaleza. Se as mulheres brasileiras denunciam essas situações e dirigem-se à delegacia, as mulheres africanas parecem consentir tal violência. Assim, torna-se necessária uma pesquisa sobre a violência no namoro e no ficar com homens africanos e, o diferencial nas reações entre mulheres africanas e brasileiras diante da violência.

\section{Considerações finais}

Neste artigo, analisei as interações afetivas vivenciadas por jovens africanos de ambos os sexos, no contexto da imigração estudantil em Fortaleza. Até ao momento, concluo que as festas e as relações afetivas abrem preciosas janelas para apreciar e compreender processos de negociações identitárias em relação à classe, raça, gênero, sexualidade e outros atributos, engendrados pelos estudantes africanos na diáspora.

Nesse cenário migratório, percebo que os jovens africanos têm preferência por mulheres brasileiras brancas em detrimento das negras e africanas. Essas preferências, fundadas em determinados atributos tidos como desejáveis, encarnam múltiplas expressões discriminatórias. Durante as interações, tais atributos se sobrepõem e se intersectam criando correlações diversas que atingem homens e mulheres de formas distintas. Nesses processos, os homens acabam por experienciar posições inversas que as assumidas no contexto de suas terras de origem. 
Nesse deslocamento, as mulheres ocupam uma condição peculiar, apresentando experiências, dramas sociais e interseccionalidades diferentes das dos homens. Sua condição de negras e imigrantes coloca-as numa posição de subalternidade no mercado afetivo. As moças se envolvem em nítidas relações de submissão, a envolver dependência econômico-financeira, em seus relacionamentos tanto com africanos como com homens brasileiros. Mesmo diante de dificuldades, elas apresentam suas estratégias, como a escolha de parceiros com melhores condições financeiras, que contribuam no pagamento de despesas.

Entretanto, tais relações entre africanos e africanas e entre africano(a)s e brasileiro(a) não estão isentas de choques culturais, assim como de relações de poder e dominação. Mesmo assim, esses padrões de interações não impedem os sujeitos de negociar suas posições sociais.

\section{Referências bibliográficas}

Baessa, Manuel (2005). Estudantes africanos: um estudo sobre o conflito e a cooperação entre os estudantes cabo verdianos e guineenses em Fortaleza. Monografia apresentada ao Departamento de Ciências Sociais da Universidade Federal do Ceará-CE (Mimeo).

Berquó, Elza (1987). Nupcialidade da População Negra no Brasil. Campinas: NEPO UNICAMP.

Bhabha, Homi (2010). O Local da Cultura. $5^{\text {a }}$ reimp. Belo Horizonte: Editora UFMG.

Bourdieu, Pierre (2008). A Distinção: crítica social do julgamento. $1^{\text {a }}$ reimp. São Paulo: Edusp.

Bourdieu, Pierre (2003). Questões de sociologia. Lisboa: Fim de Século, 2003.

Bourdieu, Pierre (2002). A Dominação Masculina. $2^{\mathrm{a}}$ ed. Rio de Janeiro: Bertrand Brasil.

Brás, Janaína (2011). [Estudantes] Africanos na Capital sentem 'na pele' o preconceito. O Povo, Fortaleza, 22 de ago. 2011. Especial, p. 4.

Cantalice, Tiago (2009). "Dando um Banho de Carinho!"- os caça-gringas e as interações afetivo-sexuais em contextos de viagem turística (Pipa-RN). Dissertação de Mestrado em Antropologia apresentada à Universidade Federal de Pernambuco- RE.

Crenshaw, Kimberlé (2002). "Documento para o encontro de especialistas em aspectos da discriminação racial relativos ao gênero". Revista Estudos Feministas, v.10, n.oo1, jan. p. 171-188.

Dawsey, John (2005). "Victor Turner e a Antropologia da Experiência". Revista Cadernos de Campo, n. 13, p. 163-176.

De Certeau, Michel (1998). A invenção do cotidiano: artes de fazer. $3^{\mathrm{a}}$ ed. Petrópolis: Vozes. 
Du Bois, W. (2007). The Negro. Pennsylvania: The Pennsylvania State University.

Elias, Norbert \& Scotson, John (2000). Os estabelecidos e os outsiders: sociologia das relações de poder a partir de uma pequena comunidade. Tradução Vera Ribeiro. Rio de Janeiro: Jorge Zahar Editores.

Fanon, Frantz (1983). Pele Negra, Máscaras Brancas. Tradução de Caldas, Adriano. Rio de Janeiro: Fator.

Guiot, Olivier (2009). Os Processos de Negociações Identitárias nas Culturas Expressivas Juvenis: o caso do kuduro na Área Metropolitana de Lisboa. Dissertação de Mestrado em Imigrações Inter-Etnicidades e Transnacionalismos apresentada na Universidade Nova de Lisboa.

Gilroy, Paul (2001). O Atlântico Negro: modernidade e dupla consciência. Tradução de Moreira, Cid. São Paulo: Editora 34, Rio de Janeiro: Universidade Cândido Mendes, Centro de Estudos Afro-Asiáticos.

Gusmão, Neusa (2006). Os Filhos de África em Portugal: antropologia, multiculturalidade e educação. $2^{\mathrm{a}}$ ed. Belo Horizonte: Autêntica.

Hall, Stuart (2011). "Pensando a diáspora: reflexões sobre a terra no exterior". In Hall. Stuart. Da Diáspora: identidades e mediações culturais. (Org.) SOVIK, Liv. $1^{\text {a }}$ ed. atual. Belo Horizonte: UFMG, p. 25-48.

Itamaraty (2002). Ministério das Relações Exteriores. Divisão de Temas Educacionais. Programa PEC-G. disponível em http://www.dce.mre.gov.br/PEC/G/historico.html. Acesso em: mai 2012.

Memmi, Albert (2007). O Imigrante. Retrato do Descolonizado árabe-muçulmano e outros. Rio de Janeiro: Civilização Brasileira, cap. 2, p. 99-185.

Mendes, Pedro (2010). Racismo no Ceará: herança colonial, trajetórias contemporâneas. Monografia em Bacharelado Ciências Sociais apresentada à Universidade Federal do Ceará, Fortaleza.

Mourão, Daniele (2009). Identidades em Trânsito: África "na pasajen" identidades e nacionalidades guineenses e cabo-verdianas. Campinas: Arte escrita.

Piscitelli, Adriana (2008). "Interseccionalidades, categorias de articulação e experiências de migrantes brasileiras". Revista Sociedade e Cultura, v.11, n.2, jul/dez. p. 263-274.

Piscitelli, Adriana (2011). "Introdução: transitando através de fronteiras". In Piscitelli, Adriana et al. (Orgs.). Gênero, sexo, amor e dinheiro: mobilidades transnacionais envolvendo o Brasil. Campinas/São Paulo: UNICAMP/PAGU, p. 5-30.

São Paulo (Prefeitura) (2011). "Análise do Quesito Raça/Cor a partir de Sistemas de Informação da Saúde do SUS”. Boletim CEInfo Análise, ano vi, n. 5, maio.

Silva Souza, Claudete (2008). A Solidão da Mulher Negra: sua subjetividade e seu preterimento pelo homem negro em São Paulo. Dissertação de Mestrado em Ciências Sociais apresentada à Pontifícia Universidade Católica, São Paulo.

Turner, Victor (1974). O Processo Ritual: estrutura e anti-estrutura. Petrópolis, Rio de Janeiro: Vozes. 
Turner, Victor (2005). "Dewey, Dilthey e Drama: um ensaio em Antropologia da Experiência (primeira parte), de Victor Turner”. Tradução de RODRIGUES, Herbert, (Rev.) DAWSEY, John. Revista Cadernos de Campo, n. 13, p. 177-185.

Ercílio Langa é Doutorando e Mestre em Sociologia pela Universidade Federal do Ceará (UFC, Brasil). Foi bolsista de produtividade do CNPq no período 2010-2012 e, é bolsista CAPES desde o ano de 2013. Tem Bacharelato em Ciências Sociais e Licenciatura em Sociologia pela Universidade Eduardo Mondlane (UEM, Moçambique).

ercilio.langa@gmail.com 